일반논문-11-16-1-02

$$
\begin{gathered}
\text { 다중분광 영상의 색상별 스펙트럼 영역을 고려한 웨이블릿 변역 } \\
\text { IKONOS 위성영상 융합 알고리즘 }
\end{gathered}
$$

이 영 건 ${ }^{\mathrm{a})}$, 국 중 갑 ${ }^{\mathrm{b})}$, 조 남 익 ${ }^{\mathrm{b} \neq}$

\title{
A Wavelet-Domain IKONOS Satellite Image Fusion Algorithm Considering the Spectrum Range of Multispectral Images
}

\author{
Young Gun Lee ${ }^{\mathrm{a})}$, Jung Gap $\mathrm{Kuk}^{\mathrm{b})}$, and Nam Ik Cho ${ }^{\mathrm{b}{ }^{\ddagger}}$
}

요 약

기존의 대표적인 위성영상 융합방법들의 경우 해상도가 높은 팬크로매틱 영상에서 얻은 고주파수 성분을 모든 저해상도의 다중분광 영상 (Color성분/IR성분 등)마다 똑같이 더함으로써 고화질의 컬러 위성영상을 합성하였다. 그러나 다중분광영상들의 스펙트럼을 살펴 보면 각 채널마다 대역폭이 서로 다르고 평균적인 밝기도 서로 다르므로 기존의 방법에서와 같이 각 성분에 동일한 고주파 성분을 더 하면 일부 다중분광영상이 왜곡되어 전체적인 컬러가 왜곡되는 현상이 나타난다. 따라서 본 논문에서는 이러한 밝기와 스펙트럼 중첩 의 차이를 보상하는 새로운 웨이블릿 변역 위성영상합성 알고리즘을 제안한다. 구체적으로, 각 다중분광영상의 밝기차이를 보정하기 위하여 서로의 명암비를 고려하면서 팬크로매틱 영상으로부터 각 채널의 고해상도 영상을 합성하는 방법을 제안한다. 그리고 다중분광 영상들 사이의 대역폭 차이를 보정하기 위한 방안으로서 각각의 웨이블릿 계수를 구하여 이들을 웨이블릿 변역에서 대역폭에 비례한 상수를 곱해서 고주파 성분을 더해주는 방법을 제시하였다. 실험은 스펙트럼의 특성이 잘 알려진 IKONOS 위성영상에 대하여 수행하 였으며, 실험 결과 제안하는 알고리즘이 PSNR과 상관도 평가에서 기존의 방법보다 더 좋다는 것을 확인하였다.

\section{Abstract}

The conventional satellite image fusion methods usually add the same amount of higher frequency components extracted from the panchromatic image to all the multispectral images. However, it is noted that each of multispectral images has different amount of overlap with the panchromatic image in terms of its spectrum, and also has different intensities. Thus giving the same amount of high frequency contents to all the spectral bands does not match with this observation, which causes color distortion in the fused image. In this paper, we propose a new wavelet-domain satellite image fusion algorithm that can compensate for these differences in intensity and spectrum overlap. For the compensation of intensity differences, we first estimate the high resolution multispectral images from P, considering the relative intensity ratios. For the compensation of the amount of spectral overlap, their wavelet coefficients are appended to the conventional wavelet-domain method where the coefficients for the addition is determined by the amount of spectrum overlap. Experiments are conducted for the IKONOS satellite images whose spectrums are well known, and the results show that the proposed algorithm gives higher PSNR and correlation coefficients compared to the conventional methods.

Keyword : IKONOS satellite image, wavelet domain, multispectral image, spectral bands 


\section{I. 서 론}

인공위성에서의 광학영상 입력시스템은 여러 가지 물리 적인 제약으로 인하여 일반 카메라와는 많이 다른 방법으 로 영상을 취득한다 ${ }^{[1]}$. 즉, 센서로 들어오는 에너지가 일반 카메라의 경우에 비하여 매우 적으며 지상으로 데이터를 전송하기 위한 대역폭이 매우 제한되어 있기 때문에 위성 에서의 영상취득은 일반적으로 밝기 성분에 해당하는 팬크 로매틱 영상 (P-Panchromatic)만을 최대 해상도로 얻고 다 른 색상밴드(R-Red, G-Green, B-Blue)나 근적외선(NIRNear Infra Red)에 해당하는 다중분광영상들은 낮은 해상 도로 취득한다. 따라서 수신측에서는 이 영상들을 융합하 여 고해상도의 컬러영상을 합성해야 하며, 이 과정을 위성 영상융합이라 한다 ${ }^{[2]}$.

지금까지 사용되어 온 융합방법들은 크게 나누어, 명암색조-채도 (IHS : Intensity Hue Saturation) 방법 ${ }^{[3]-[5]}$, 주요 성분 분석 (PCA : Principal Component Analysis) 방법 ${ }^{[6-[7]}$, 그리고 웨이블릿 변역 방법 ${ }^{[8]-[12]}$ 의 세 가지 접근방법 으로 분류할 수 있으며, 이 방법들 중에 IHS 방법이 계산량 이 적어서 가장 널리 사용되고 있다 ${ }^{[13]}$. 이 방법에서는 우선 $\mathrm{R}, \mathrm{G}, \mathrm{B}$ 채널 영상 각각의 크기를 $\mathrm{P}$ 와 동일한 크기로 보간 을 하고 이들의 조합을 $\mathrm{I}, \mathrm{H}, \mathrm{S}$ 성분으로 변환한 후, 변환된 $\mathrm{I}$ 성분을 단순히 $\mathrm{P}$ 로 교체함으로써 해상도가 높아진 I 성분 이 된 것으로 간주하며, 이를 다시 RGB로 역변환 하여 고 해상도의 컬러영상을 얻는다 ${ }^{[14]}$. PCA 방법에서는 우선 다 중분광영상을 고유치 분석으로 분해한다. 최대 고유치에 해당하는 성분이 밝기 성분으로 간주되고, IHS 방법에서와 마찬가지로 이를 $\mathrm{P}$ 로 교체한다 ${ }^{[3],[15]}$. 이상에서 언급한 IHS 방법이나 PCA 방법의 경우, I 성분 또는 PCA의 첫 성분이 실제로 $\mathrm{P}$ 와 동일하지 않기 때문에 융합된 컬러영상에 상당 한 색상정보의 왜곡이 나타난다는 문제가 있다 ${ }^{[7]}$.

a) 공군사관학교 전자전산학과

Dept. of Electrical Engineering and Computer Science, Korea Air Force Academy

b) 서울대학교 전기컴퓨터공학부

Dept. of Electrical and Computer Engineering, Seoul National Univ.

\# 교신저자 : 조남익 (nicho@snu.ac.kr)

※ 본 연구는 방위산업청과 국방과학연구소의 기초연구과제(UD080015FD)의 지원에 의하여 수행된 결과의 일부입니다. 지원에 감사드립니다.

- 접수일(2010년7월19일), 수정일(2011년1월3일), 게재확정일(2011년1월6일)
색상정보 왜곡을 중요시하는 경우, 웨이블릿 변역에서의 방법이 IHS나 PCA에 비하여 왜곡이 적어 선호되고 있다 [10]-[11]. 이 방법의 약점은 IHS 방법보다 계산량이 많다는 것이지만, 최근 컴퓨터들의 성능을 고려하면 그다지 큰 문 제는 아닌 것으로 판단된다. 이 방법에서는 우선 $\mathrm{P}$ 를 웨이 블릿 필터를 이용하여 부대역으로 분해하는데, 가장 낮은 대역(스케일 상수 대역)의 해상도가 다중분광영상의 해상 도와 같아질 때까지 분해한다. 예를 들어 다중분광영상의 해상도가 $\mathrm{P}$ 의 4 분의 1 일 때, 웨이블릿 변환을 두 차례 적용 한다. 변환된 대역들 중에서 가장 낮은 대역을 R과 교체하 고 이를 역 웨이블릿 변환한 것이 고해상도의 R이라 간주 된다. 이는 R 성분의 고주파 성분이 원래는 없지만, 이것이 $\mathrm{P}$ 의 고주파 성분과 동일할 것이라 가정하여 더한 것이나 마찬가지이다. 다른 성분의 영상들 $(\mathrm{G}, \mathrm{B}, \mathrm{NIR})$ 도 동일한 방법으로 얻어지며 따라서 이러한 기존의 방법은 모든 다 중분광 성분에 동일한 크기의 고주파 성분이 더해진 결과 이다 ${ }^{[10]-[11]}$. 그러나 앞에서 언급한 바와 같이 $\mathrm{R}, \mathrm{G}, \mathrm{B}$ 각 성분들은 $\mathrm{P}$ 성분과 겹치는 대역폭이 서로 다르며 전체적인 평균 밝기 또한 다르다. 구체적인 예로, 그림 1 은 IKONOS 위성영상 각 채널의 상대적인 분광응답을 보여준다. 여기 서 $\mathrm{R}$ 과 $\mathrm{NIR}$ 채널은 거의 $\mathrm{P}$ 의 범위 안에 있지만 $\mathrm{B}$ 와 $\mathrm{G}$ 는 그렇지 않은 것을 볼 수 있다. 따라서 본 논문에서는, 위성 영상융합 시에 모든 다중분광 성분에 P에서 추출된 고주파 성분을 똑같은 양으로 더하는 것보다는, 각 성분의 밝기와 스펙트럼 중첩의 관계를 고려한 양 만큼 고주파 성분을 더 하는 것이 왜곡을 줄일 수 있을 것이라 생각하여 새로운 알고리즘을 제안한다. 이를 위하여 우선 P에서 각 화소의 상대적인 명암에 의한 고주파수 성분을 얻어내어 각 성분 의 밝기 차이가 보정된 고해상도 영상을 만든다. 그리고 웨 이블릿 계수를 더함에 있어서도 기존의 웨이블릿 방법과 달리 분광응답들이 P 성분의 스펙트럼과 중첩된 양을 고려 하여 더해지도록 한다. 즉, 웨이블릿 상수에 분광응답 중첩 의 양에 역 비례하게 새로 고안한 가중치를 곱하는 것이다. 예를 들면, 그림 1에서 보듯이 IKONOS에 사용된 영상정보 취득 센서의 분광응답에서 $\mathrm{R}$ 은 거의 $\mathrm{P}$ 의 분광응답 영역 안 에 있기 때문에, 웨이블릿 상수를 더하는 과정에 있어 기존 의 방법과 같이 해도 충분하다. 즉 P에서 얻어낸 정보로 충 
분히 고주파 성분이 추정되는 것이라고 할 수 있다. 하지만 $\mathrm{G}$ 와 $\mathrm{B}$ 의 경우 $\mathrm{P}$ 의 영역에서 많이 벗어나 있어서 $\mathrm{P}$ 로부터 얻어진 계수보다 앞의 과정에서 얻어진 고해상도 $\mathrm{G}, \mathrm{B}$ 로부 터 얻어지는 계수에 더 큰 가중치를 주어서 더한다. 여러 가지 위성영상에 대하여 제안된 방법을 실험해 본 결과, 기 존의 방법들보다 제안하는 알고리즘을 이용하여 더 높은 PSNR(Peak Signal to Noise Ratio)과 CC(Cross Correlation)를 얻을 수 있다는 것을 확인하였다.

본 논문의 나머지 부분은 다음과 같다. 2 장에서는 우선 사용될 표기법을 요약하고, 기존의 웨이블릿을 기초로 한 영상융합방법을 설명한다. 제안하는 알고리즘은 3 장에서 설명하고, 실험결과는 4 장에 정리한다.

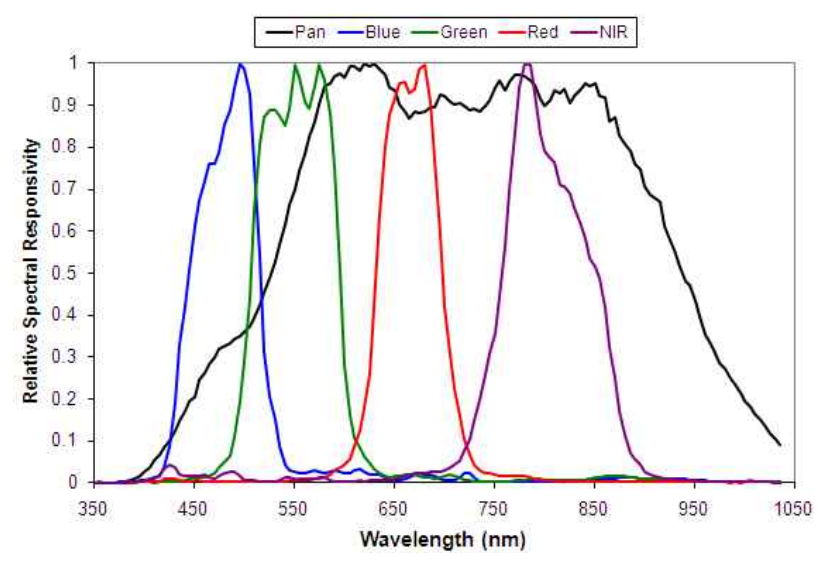

그림 1. IKONOS 위성영상의 상대적인 분광응답 (출처: http://www.geoeye. com)

Fig. 1. IKONOS relative spectral response (source : http://www.geoeye. com).

\section{II. 웨이블릿 변역 위성영상 융합법}

기존의 웨이블릿 변역 영상융합 알고리즘을 소개하기 전 에 우선 본 논문에서 사용될 표기법과 축약어들을 다음과 같이 정리하였다.

\section{1. 표기법}

$\mathrm{P}$ 는 팬크로매틱 영상을 의미하고, $\left\{R^{L}, G^{L}, B^{L}, N^{L}\right\}$ 은
원래의 \{Red, Green, Blue, NIR\} 성분을 나타낸다 (원래 신호가 저해상도임을 강조하기 위하여 첨자 $\mathrm{L}$ 을 사용하였 다). $\left\{R^{E}, G^{E}, B^{E}, N^{E}\right\}$ 는 $\left\{R^{L}, G^{L}, B^{L}, N^{L}\right\}$ 를 P와 같은 크 기로 확대(보간)한 영상을 나타낸다. $\left\{R^{H}, G^{H}, B^{H}\right\}$ 는 P에 서 상대적인 명암비율을 고려하여 밝기를 보정한 고해상도 의 컬러영상이다. 그리고 $\{\hat{R}, \hat{G}, \hat{B}\}$ 는 웨이블릿 변역에서 융합한 최종 고해상도의 컬러영상이다. 이 표기법들은 각 각 2 차원의 행렬이고, 행렬의 구성요소들은 화소의 명암을 나타낸다. 앞에서 언급한 바와 같이 고해상도 영상인 $\mathrm{P}$ 의 크기가 가장 크고, ${ }^{L}$ 이 붙은 행렬은 보통 $\mathrm{P}$ 의 4 분의 1 크기 이다. $R^{L}$ 을 $R^{E}$ 로 보간할 때(다른 채널도 마찬가지로), 간 단한 쌍일차 변환 접근법을 사용한다 ${ }^{[19]}$. 보다 나은 성능을 위해 더 정교한 보간 혹은 초해상도 방법 역시 사용할 수 있다.

다음은 밝기 보상을 위한 파라미터들과 웨이블릿 계수행 렬을 정의한다. 이를 위하여 우선 $\left\{R^{E}, G^{E}, B^{E}, N^{E}\right\}$ 의 평 균 화소값들을 $\{r, g, b, n\}$ 로 정의한다. 이 모든 요소들의 평 균은 $m$ 으로 표기하고 상대적인 명암들은 $\{\alpha, \beta, \gamma, \delta\}$ 로 표 기한다. 이를 식으로 나타내면 아래와 같다 :

$$
\begin{gathered}
m=\frac{r+g+b+n}{4} \\
\alpha=\frac{r}{m}, \beta=\frac{g}{m}, \gamma=\frac{b}{m}, \delta=\frac{n}{m} .
\end{gathered}
$$

마지막으로 $w_{P}^{l}$ 는 $\mathrm{P}$ 행렬의 웨이블릿 계수 중 $l$ 번째 밴드 를 나타낸다. 또한 영상융합에서는 각 웨이블릿 대역의 크 기를 줄이지 않으므로 $w_{P}^{l}$ 는 $\mathrm{P}$ 와 같은 크기의 행렬이다.

\section{2. 기존의 웨이블릿 변역 융합 알고리즘}

기존의 여러 웨이블릿 분해 방법 중 본 논문에서는 전통 적인 융합 알고리즘에서 가장 많이 사용되는 átrous 방 법 ${ }^{[10][11],[16]}$ 을 변형하고 비교 대상으로 한다. 이 방법에서는 $B_{3}$ (3차 스플라인 함수)가 웨이블릿 분해를 위한 스케일링 함수로 사용된다 ${ }^{[17]}$. 구체적으로, 주어진 영상과 $B_{3}$ 의 컨벌 루션 결과는 첫 번째 스케일 상수이고, 이 스케일 상수와 
주어진 영상의 차는 첫 번째 밴드의 웨이블릿 계수에 해당 한다. 이 과정은 보다 높은 차수의 스케일 상수와 웨이블릿 상수를 만들어 내기 위해 스케일 상수에 대해 반복된다. 팬 크로매틱 영상의 웨이블릿 분해는 다음 과정과 같이 표기 할 수 있다.

$$
P=P^{M}+\sum_{l=1}^{M} w_{P}^{l}
$$

여기서 $P^{M}$ 은 $M$ 번째 스케일 상수를 의미하고, 남은 표 기는 이전 영상과 스케일 상수의 차를 의미한다.

기존의 웨이블릿 변역 융합 알고리즘들 중 가장 널리 알 려진 $\mathrm{AWRGB}{ }^{[11]}$ 에서는 모든 다중분광영상 채널들은 먼저 $\mathrm{P}$ 와 같은 크기로 보간된다. 앞서 서술했듯이 보간 과정은 간단한 쌍일차 보간법으로 충분하며, 보다 복잡한 방법을 적용하는 경우 성능이 조금 개선되기는 하지만 성능차이가 크지는 않다 ${ }^{[19][20]}$. 이렇게 쌍일차 보간법으로 보간된 다중 분광영상 $R^{E}, G^{E}, B^{E}, N^{E}$ 는 (실제로는 존재하지 않는) 고해상도 다중분광 영상의 근사값으로 간주된다. 그러므로 고해상도 영상들은 다음과 같이 얻을 수 있다.

$$
\hat{R}=R^{E}+\sum_{l=1}^{L} w_{P}^{l}, \hat{G}=G^{E}+\sum_{l=1}^{L} w_{P}^{l}, \hat{B}=B^{E}+\sum_{l=1}^{L} w_{P}^{l} .
$$

이 식에서 보는 바와 같이 기존의 AWRGB 알고리즘에 서는 고주파 성분 (P에서 추출한 웨이블릿 계수들)이 모든 색상성분에 똑같은 양만큼 더해진다.

\section{III. 제안하는 알고리즘}

보통 다중분광영상 각 채널의 평균 명암값과 $\mathrm{P}$ 와 중첩되 는 분광응답 영역은 그림 1 에서 볼 수 있듯이 채널별로 각 각 다르다. 따라서 제안된 알고리즘에서는 이러한 차이를 고려하여 서로 다른 양의 웨이블릿 계수를 더하고자 한다. 구체적으로, 식(4)의 기존의 웨이블릿 계수 합산법에 추가 적으로 밝기가 보정된 고주파 성분을 스펙트럼 중첩의 양
을 고려하여 더하고자 한다. 즉, 제안하는 알고리즘을 정리 하면 그림 2에서와 같이 저해상도 영상의 보간, 밝기보정된 고해상도 영상 추정, 이들로부터 웨이블릿 계수 추출, 그리 고 스펙트럼 중첩을 고려한 웨이블릿 계수 더하기의 네 단 계로 수행된다. 이 과정들 중에 영상보간은 앞에서 언급한 바와 같이 단순한 쌍일차 보간 방법으로 수행된다. 다음은 나머지 과정들을 순서대로 설명한다.

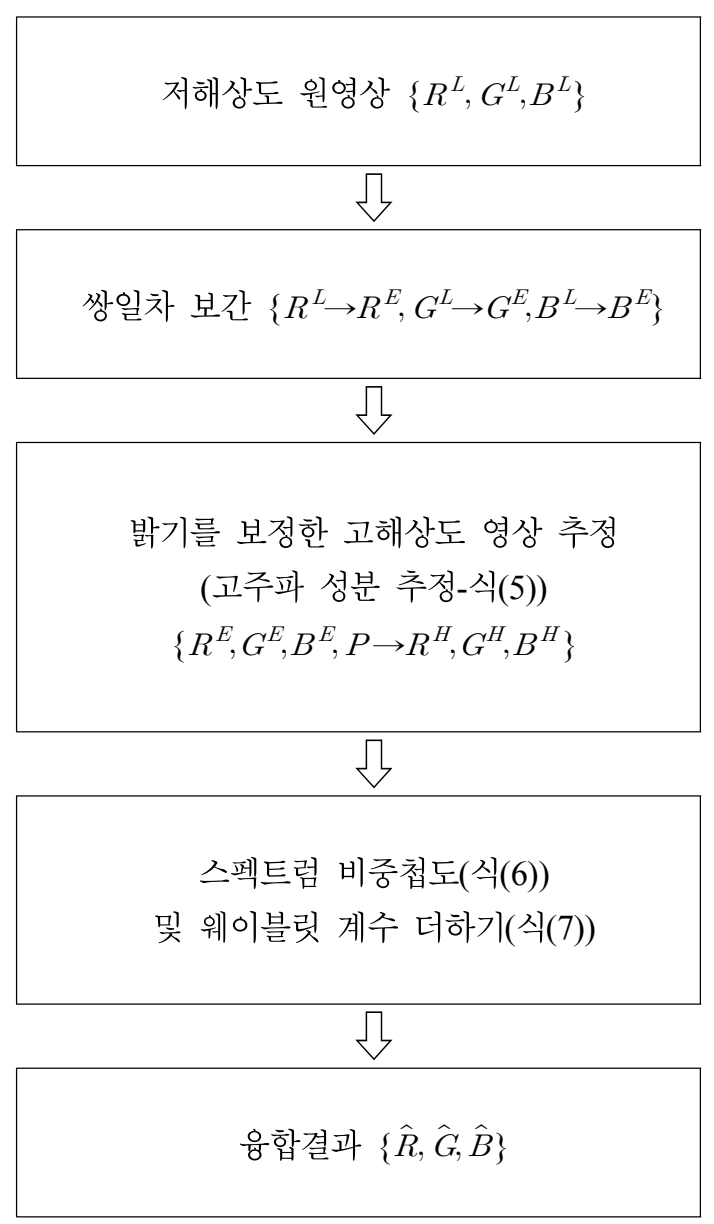

그림 2. 제안하는 방법의 순서도

Fig. 2. Flow chart of the proposed algorithm

\section{1. 밝기를 고려한 고해상도 영상 추정}

처음 과정인 영상보간 과정을 통하여 $\left\{R^{L}, G^{L}, B^{L}, N^{L}\right\}$ 
로부터 P와 크기가 같은 $\left\{R^{E}, G^{E}, B^{E}, N^{E}\right\}$ 를 얻었다. 기 존의 방법에서는 식(4)에 나타난 바와 같이 여기에 팬크로 매틱 영상으로부터 얻은 고주파 성분을 똑같이 더했다. 그 러나 각 성분의 밝기가 차이가 있는데도 똑같은 양의 고주 파 성분을 더한다면 당연히 각 컬러성분 비가 왜곡되어 결 국 전체적인 컬러가 왜곡되는 결과를 가져온다. 따라서 본 논문에서는 각 컬러성분들의 밝기 비에 따라 고주파 성분 의 크기를 다르게 더해주고자 한다. 예를 들어, 전체 밝기에 비하여 R 성분의 크기가 작다면 R 성분에는 고주파 성분이 그만큼 적게 더해져야 하므로 II장의 식 (1)과 (2)에서와 같 은 과정으로 각 성분의 밝기 비를 구하고 이를 이용하여 다음 식과 같이 밝기의 상대값에 비례한 고주파 성분을 구 한다.

$$
\begin{aligned}
& R^{H}(i, j)=\frac{\alpha R^{E}(i, j)}{\alpha R^{E}(i, j)+\beta G^{E}(i, j)+\gamma B^{E}(i, j)+\delta N^{E}(i, j)} \times P(i, j) \\
& G^{H}(i, j)=\frac{\beta G^{E}(i, j)}{\alpha R^{E}(i, j)+\beta G^{E}(i, j)+\gamma B^{E}(i, j)+\delta N^{E}(i, j)} \times P(i, j) \\
& B^{H}(i, j)=\frac{\gamma B^{E}(i, j)}{\alpha R^{E}(i, j)+\beta G^{E}(i, j)+\gamma B^{E}(i, j)+\delta N^{E}(i, j)} \times P(i, j)
\end{aligned}
$$

여기서 $A(i, j)$ 는 $\mathrm{A}$ 행렬의 $(i, j)$ 번째 원소를 나타낸다. 그리고 2장의 표기법에서 설명한 바와 같이 $\{\alpha, \beta, \gamma, \delta\}$ 는 각 성분들의 상대적인 밝기를 나타내는 파라미터이다. 예 를 들어 $r\left(R^{E}\right.$ 의 평균 화소명암값)이 $m$ (모든 성분의 평균 화소명암 값) 보다 클 때, $\mathrm{P}$ 영상의 같은 화소에서 R 채널 성분은 다른 성분들 보다 큰 비율을 차지해야 하며 이때 $\alpha=r / m$ 이 1 보다 크므로 $\mathrm{R}$ 성분에 이를 곱함으로써 이러 한 밝기차이가 고려되는 것이다. 이렇게 얻어진 각 성분의 고해상도 영상은 $P(i, j)$ 로부터 얻어진 고주파 성분을 갖고 있되, 각 성분의 상대적인 밝기값에 따라 다른 양을 갖게 된다.

\section{2. 스펙트럼 비중첩도 계산 및 덧셈 기중치}

다음 과정은, 이와 같이 상대적인 밝기를 고려하여 추정 된 고해상도 영상들로부터 웨이블릿 계수를 구하고 이를 기존의 웨이블릿 덧셈 과정에 추가하는 것이다. 이 과정에
서도 앞에서 언급한 바와 같이 기존의 방법과는 달리 각 성분의 스펙트럼이 $\mathrm{P}$ 의 스펙트럼과 얼마나 중첩되는가를 고려하여 더하도록 한다 (그림 1). 예를 들어 R 채널의 경 우, $\mathrm{P}$ 의 영역 내에 있으므로 기존의 방법에 특별히 추가할 고주파수 성분이 없지만, $\mathrm{G}$ 와 $\mathrm{B}$ 의 경우 그들의 에너지 중 많은 양이 P 영역 안에 있지 않으므로 위에서 기존의 방법 에서 더하는 양 보다는 더 많은 고주파 성분을 더해야 할 것으로 판단된다. 즉, $\mathrm{G}$ 와 $\mathrm{B}$ 채널에 $\mathrm{P}$ 로 부터 얻은 고주파 수 성분을 더할 때 중첩되는 영역의 넓이에 반비례한 양을 더하도록 한다. 이를 위해, 각 성분의 스펙트럼이 $\mathrm{P}$ 로부터 얼마나 독립적인지를 나타내는 스펙트럼 비중첩도를 다음 과 같이 정의한다 (B의 경우).

$$
T_{B}=\frac{\int_{B_{i}}^{B_{f}}\left(f_{B}(\omega)-f_{P}(\omega)\right) d \omega}{\int_{B_{i}}^{B_{f}} f_{P}(\omega) d \omega}
$$

여기서 $f_{B}(\omega)$ 와 $f_{P}(\omega)$ 는 각각 그림 1에서의 $\mathrm{B}$ 와 $\mathrm{P}$ 스 펙트럼 그래프를 의미하고, $\left[B_{i}, B_{f}\right]$ 는 $\mathrm{B}$ 성분이 차지하는 주파수 범위를 의미한다. 이 식에서 알 수 있는 바와 같이 비중첩도가 크다는 것은 그 성분이 $\mathrm{P}$ 와 별로 겹치는 부분이 없다는 것이다. 이와 같은 방법으로 각 채널별로 측정해서 $T_{R}$ 과 $T_{G}$ 를 각각 구한다. 이때 $T$ 값의 범위는 $[0, \infty]$ 이다. $\mathrm{P}$ 와 다중분광영상의 스펙트럼이 전혀 겹치지 않는다면 분 모의 값이 0 이 되어 $T=\infty$ 가 되고, 다중분광영상의 스펙트 럼이 완전히 P 영역에 속한다면, 분자의 값이 0 이 되어 $T$ $=0$ 이다. 위의 적분 계산을 정확하게 하기위해 각 그래프의 식이 필요한데, 이것을 구하는 것은 불가능하다. 대신 각 채널별 그래프의 크기를 나타낸 파일 "IKONOS_Relative_ Spectral_Response.xls"을 GeoEye(http://www.geoeye.com) 에서 받아서 각 스펙트럼의 샘플값을 얻을 수 있었다. 이 표로부터 구한 각 성분의 비중첩도는 $T_{R}=0.023, T_{G}$ $=0.25, T_{B}=1.2$ 과 같이 나오며 이 값이 작을수록 $\mathrm{P}$ 성분과 겹치는 양이 많고, 클수록 $\mathrm{P}$ 성분과 겹치지 않는다는 것을 나타내므로 이 값이 웨이블릿 계수를 더하는 양을 나타낸 
다. 즉, 최종 영상융합 결과는 다음과 같이 기존의 웨이블 릿 덧셈에 새로이 구한 성분의 웨이블릿 계수를 비중첩도 를 고려하여 다음과 같이 더해서 얻어진다.

$$
\begin{aligned}
& \hat{R}=R^{E}+\frac{1}{1+T_{R}}\left(\sum_{l=1}^{L} w_{P}^{l}+T_{R} \sum_{l=1}^{L} w_{R^{H}}^{l}\right) \\
& \hat{G}=G^{E}+\frac{1}{1+T_{G}}\left(\sum_{l=1}^{L} w_{P}^{l}+T_{G} \sum_{l=1}^{L} w_{G^{H}}^{l}\right) \\
& \hat{B}=B^{E}+\frac{1}{1+T_{B}}\left(\sum_{l=1}^{L} w_{P}^{l}+T_{B} \sum_{l=1}^{L} w_{B^{H}}^{l}\right)
\end{aligned}
$$

$T$ 값에 따른 계산을 해보면, $T=\infty$ 일 때는 $R^{H}$ 의 성분만 이 더해지고, $T=0$ 일 때는 $\mathrm{P}$ 의 성분을 그대로 더하게 된 다. 이것은 $\mathrm{P}$ 와 다중분광영상의 스펙트럼이 전혀 겹치지 않을 때 $\mathrm{P}$ 의 정보를 제외하고, 다중분광영상의 스펙트럼 이 $\mathrm{P}$ 에 속할 때 모든 정보가 $\mathrm{P}$ 에 있어서 $\mathrm{P}$ 의 성분을 그대 로 더하는 것으로 올바른 결과이다. 여기서 $w_{R^{H}}^{l}$ 는 $R^{H}$ 의 $l$ 번째 밴드 웨이블릿 계수를 의미하고, 다른 표기들도 이 와 같다.

\section{IV. 실험 결과}

제안한 알고리즘을 IKONOS 영상 총 12 개 세트에 각각 적용하였고, 결과영상 일부를 잘라서 확대한 것을 그림 3과 4에 나타내었다. 그림 3은 제안한 방법과 IHS 영상을 비교 한 것으로서, 가운데 컬럼이 원영상이고 좌측이 기존의 IHS 방법의 결과, 오른쪽 컬럼이 제안된 방법의 결과로서 제안된 방법의 컬러가 원영상의 컬러에 더 가까운 것을 볼 수 있다. 마찬가지로 그림 4에서 가운데 컬럼이 원영상이고 좌측 컬럼은 기존의 웨이블릿 방법의 결과이고 우측 컬럼 이 제안된 방법의 결과이다. 마찬가지로 제안된 방법의 결 과가 원영상에 더 가까움을 볼 수 있다. 보다 객관적인 비교 를 위해 기존의 논문들에서와 같이 PSNR과 상관도를 계산 해 보았다 ${ }^{[2],[4],[21]}$. 이 방법들에서는 객관적인 성능비교를 위하여 현재 $R^{L}, G^{L}, B^{L}$ 가 원본이라 가정하여, $\mathrm{P}$ 를 $R^{L}$ 과 같은 크기로 줄이고 모든 컬러 채널 $R^{L}, G^{L}, B^{L}$ 을 4 분 의 1 크기로 줄인다. 그리고 융합 알고리즘을 이 영상들에 적용하여 $R^{L}, G^{L}, B^{L}$ 을 추정(융합)하고 이들을 원본과

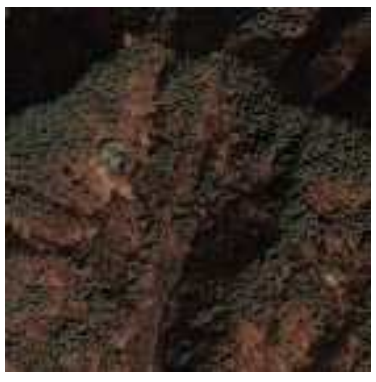

(a-1)

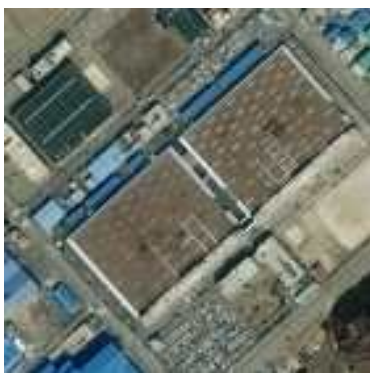

(b-1)

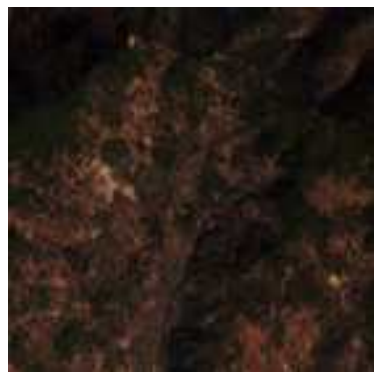

(a-2)

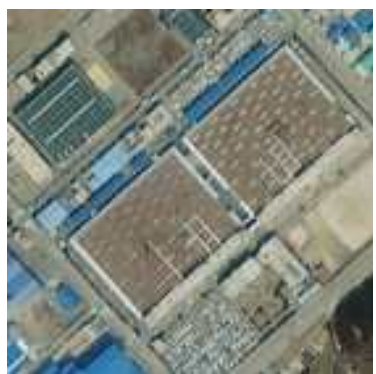

(b-2)

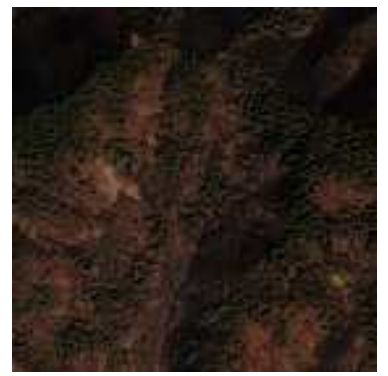

(a-3)

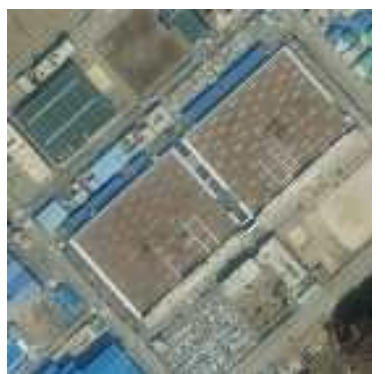

(b-3)

그림 3. IHS와 제안된 방법의 비교. 가운데 컬럼 (a-2)와 (b-2)가 원영상, 좌측 컬럼이 IHS방법, 우측 컬럼이 제안된 방법 Fig. 3 Comparison of IHS and proposed algorithm 


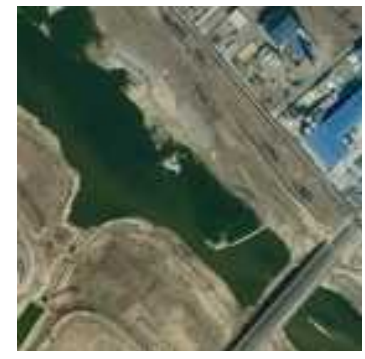

$(a-1)$

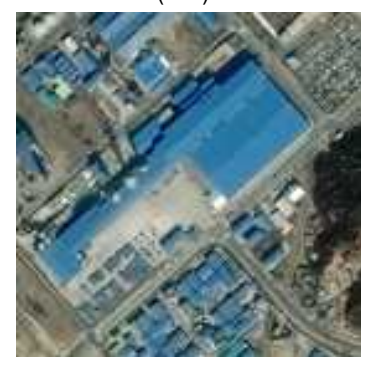

(b-1)

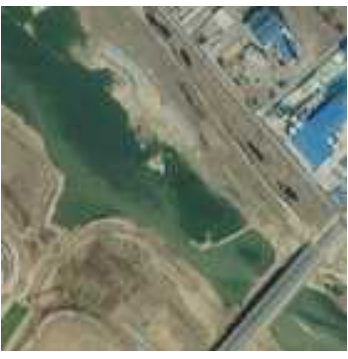

$(\mathrm{a}-2)$

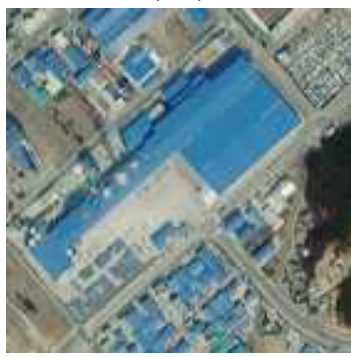

$(b-2)$

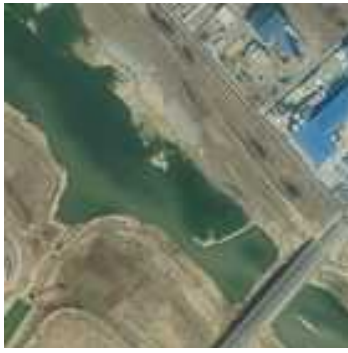

$(\mathrm{a}-3)$

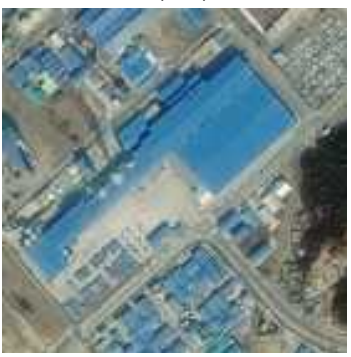

$(b-3)$

그림 4. 기존의 웨이블릿 방법과 제안된 방법의 비교. 가운데 컬럼의 (a-2), (b-2)가 원영상이고 좌측 컬럼이 기존의 방법, 오른쪽 컬럼이 제안된 방법 Fig. 4. Comparison of the conventional wavelet method and the proposed method.

비교하였다. 평가지표로 사용된 PSNR은 $A$ 와 $B$ 영상행렬 사이에
와 같이 정의하고, 여기서 $M A X$ 는 화소명암의 최대값을 의미한다. $\|A-B\|^{2}$ 는 $A$ 와 $B$ 행렬에서 각 화소의 차이 제 곱 합이다. 이 실험에서 각 색상 채널별로 위의 PSNR 계산 식에 의해 계산을 하고, 그 값들의 평균을 구해 비교하였

표1. IHS ${ }^{[4]}$, 전통적인 웨이블릿 기반 방법 ${ }^{[11]}$, 제안하는 알고리즘의 비교

Table 1. Comparison of IHS ${ }^{[4]}$, conventional wavelet based method ${ }^{[11]}$, and the proposed algorithm.

\begin{tabular}{|c|c|c|c|c|c|c|c|}
\hline 영상번호 & 사용된 방법 & PSNR & $\mathrm{CC}$ & 영상번호 & 사용된 방법 & PSNR & $\mathrm{CC}$ \\
\hline \multirow{3}{*}{1} & IHS & 21.867 & 0.918 & \multirow{3}{*}{7} & IHS & 24.780 & 0.957 \\
\hline & Wavelet & 26.197 & 0.951 & & Wavelet & 27.931 & 0.976 \\
\hline & Proposed & 26.860 & 0.958 & & Proposed & 28.520 & 0.980 \\
\hline \multirow{3}{*}{2} & IHS & 21.839 & 0.923 & \multirow{3}{*}{8} & IHS & 23.760 & 0.945 \\
\hline & Wavelet & 25.831 & 0.958 & & Wavelet & 26.368 & 0.970 \\
\hline & Proposed & 26.470 & 0.964 & & Proposed & 28.520 & 0.980 \\
\hline \multirow{3}{*}{3} & IHS & 24.227 & 0.946 & \multirow{3}{*}{9} & IHS & 21.185 & 0.941 \\
\hline & Wavelet & 27.401 & 0.974 & & Wavelet & 26.807 & 0.962 \\
\hline & Proposed & 28.278 & 0.979 & & Proposed & 27.352 & 0.967 \\
\hline \multirow{3}{*}{4} & IHS & 22.836 & 0.934 & \multirow{3}{*}{10} & IHS & 20.366 & 0.912 \\
\hline & Wavelet & 28.366 & 0.966 & & Wavelet & 24.672 & 0.934 \\
\hline & Proposed & 29.014 & 0.971 & & Proposed & 25.180 & 0.942 \\
\hline \multirow{3}{*}{5} & IHS & 24.580 & 0.953 & \multirow{3}{*}{11} & IHS & 20.018 & 0.905 \\
\hline & Wavelet & 27.662 & 0.970 & & Wavelet & 24.480 & 0.921 \\
\hline & Proposed & 28.332 & 0.980 & & Proposed & 25.067 & 0.932 \\
\hline \multirow{3}{*}{6} & IHS & 23.438 & 0.950 & \multirow{3}{*}{12} & IHS & 24.496 & 0.875 \\
\hline & Wavelet & 26.495 & 0.973 & & Wavelet & 28.188 & 0.924 \\
\hline & Proposed & 27.057 & 0.977 & & Proposed & 29.663 & 0.944 \\
\hline
\end{tabular}


다. $\mathrm{CC}$ 는 $A$ 와 $B$ 영상행렬 사이에

$$
C C=\frac{\left\|(A-\bar{A}) \cdot(B-\bar{B})^{T}\right\|}{\|A-\bar{A}\|\|B-\bar{B}\|}
$$

로 정의하고, 여기서 $\bar{A}$ 는 $A$ 행렬의 평균값을 의미한다. $A^{T}$ 는 $A$ 행렬의 전치행렬이다.

표 1 은 기존의 IHS 알고리즘 ${ }^{[4]}$ 과 웨이블릿 알고리즘 ${ }^{[1]}$, 제안하는 알고리즘을 14 개의 영상에 대해 실험한 결과이 다. 제안하는 알고리즘이 PSNR과 CC 모두에서 개선된 것 을 확인할 수 있다. 이것은 색상과 공간 왜곡이 모두 줄어든 것을 의미한다.

\section{V. 결 론}

본 논문에서는 웨이블릿에 기초한 새로운 위성영상융 합 알고리즘을 제안하였다. 기존의 웨이블릿 기반 융합방 법이 다중분광영상 모든 채널에 동일한 양의 고주파수 성 분을 더하는 것인 반면, 제안하는 방법에서는 $\mathrm{P}$ 와 다른 채널 스펙트럼의 중첩되는 면적과 상대적인 명암 값을 고 려하여 더해준다. 더해줄 고주파 성분의 경우, 기존의 방 법에서는 각 성분 모두에 동일하게 $\mathrm{P}$ 로부터 추출한 것을 더한 반면에, 본 논문에서는 상대적인 밝기를 고려한 성 분들을 만들어내어 여기서 고주파 성분을 추출하였다. 그 리고 웨이블릿 계수를 더하는 과정에서 사용되는 가중치 는 주파수 변역에서 $\mathrm{P}$ 와 컬러영상의 각 채널 사이에 얼마 나 에너지가 중첩되는가에 따라 조절된다. $\mathrm{P}$ 와 중첩되는 영역이 클 때는 이미 $\mathrm{P}$ 가 그 성분의 정보를 많이 갖고 있 음을 나타내므로 적은 가중치를 더하고, 반대로 영역이 작을 때에는 큰 가중치를 갖고 더한다. 제안하는 알고리즘 을 12 개 세트 IKONOS 영상에 실험을 하여 PSNR과 $\mathrm{CC}$ 에 서 나은 결과를 주는 것을 실험결과에서 볼 수 있고, 이는 색상정보와 공간정보가 모두 개선되었음을 의미한다.

\section{참 고 문 헌}

[1] Y. Zhang, "Understanding image fusion," Photogramm. Eng. Remote Sens., Vol. 70, no. 6, pp. 657-661, June 2004.

[2] Z. Wang, D. Ziou, C. Armenakis, D. Li, and Q. Li, "A comparative analysis of image fusion methods," IEEE Trans. Geosci. Remote Sens., vol. 43, no. 6, pp. 1391-1402, June 2005.

[3] R. Haydn, G. W. Dalke, J. Henkel, and J. E. Bare, "Applications of the IHS color transform to the processing of multisensor data and image enhancement," Proc. Int. Sym. Remote Sens. Arid. Semi-Arid Lands., pp. 595-616, January 1982.

[4] T. M. Tu, P. S. Huang, C. L. Hung, and C. P. Chang, "A fast intensityhue-saturation fusion technique with spectral adjustment for IKONOS imagery," IEEE Geosci. Remote Sens. Letters., Vol. 1, no. 4, pp. 309-312, October 2004.

[5] M. J. Choi, "A new intensity-hue-saturation fusion approach to image fusion with a tradeoff parameter," IEEE Trans. Geosci. Remote Sens., Vol. 44, no. 6, pp. 1672-1682, June 2006.

[6] M. Gonz'alez-Aud'icana, J. L. Saleta, R. G. Catal'an, and R. Garc'ia, "Fusion of multispectral and panchromatic images using improved IHS and PCA mergers based on wavelet decomposition," IEEE Trans. Geosci. Remote Sens., Vol. 42, no. 6, pp. 1291-1299, June 2004.

[7] P. S. Chavez, J. Stuart, C. Sides, and J. A. Anderson, "Comparison of three different methods to merge multiresolution and multispectral data: Landsat TM and SPOT panchromatic," Photogramm. Eng. Remote Sens., Vol. 57, no. 3, pp. 295-303, March 1991.

[8] D. A. Yocky, "Image merging and data fusion by means of the discrete two-dimensional wavelet transform," J. Opt. Soc. Amer. A., Vol. 12, no. 9, pp. 1834-1841, 1995.

[9] S. G. Mallat, "A theory for multiresolution signal decomposition: The wavelet representation," IEEE Trans. Pattern Anal. Machine Intell., Vol. 11, no. 7, pp. 674-693, July 1989.

[10] M. Gonz'alez-Aud'icana, X. Otazu, O. Fors and A. Seco, "Comparison between Mallat' the 'a trous' discrete wavelet transform based algorithms for the fusion of multispectral and panchromatic images," Int. J. Remote Sens., Vol. 26, no. 3, pp. 595-614, February 2005.

[11] J. N'u ez, X. Otazu, O. Fors, Albert Prades, Vicenc, Pal'a, and Rom'an Arbiol, "Multiresolution-based image fusion with additive wavelet decomposition," IEEE Trans Geosci. Remote Sens., Vol. 37, no. 3, pp. 1204-1211, May 1999.

[12] J. Zhou, D. L. Civco, and J. A. Silander, "A wavelet transform method to merge Landsat TM and SPOT panchromatic data," Int. J. Remote Sens., Vol. 19, no. 4, pp. 743-757, March 1998.

[13] P. S. Chavez, and J. A. Bowell, "Comparison of the spectral information content of Landsat thematic mapper and SPOT for three different sites in the Phoenix, Arizona region," Photogramm. Eng. Remote Sens., Vol. 19, no. 5, pp. 1699-1708, December 1988.

[14] W. J. Carper, T. M. Lillesand, and R. W. Kiefer, "The use of intensity-hue-saturation transformation for merging SPOT panchromatic and multispectral image data," Photogramm. Eng. Remote Sens., Vol. 56, no. 4, pp. 459-467, April 1990.

[15] V. K. Shettigara, "A generalized component substitution technique for 
spatial enhancement of multispectral images using a higher resolution dataset," Photogramm. Eng. Remote Sens., Vol. 58, no. 5, pp. 561-567, May 1992.

[16] M. Holschneider, and P. Tchamitchian, "Regularit'e local de la function 'on-defferentiable' the Riemann," In les ondelettes en 1989, P. G. Lemari'e, Ed. Paris, France: Springer-Verlag, 1990.

[17] J. L. Starck, and F. Murtagh, "Image restoration with noise suppression using the wavelet transform," Astron. Astrophys., Vol. 288, no. 1, pp. 342-348, January 1994.

[18] R. S. Blum, and Z. Liu, Multi-sensor image fusion and its applications.
Taylor and Francis, 2006.

[19] S. E. Umbaugh, Computer imaging: Digital image analysis and processing. Taylor and Francis, Ch. 9, pp. 455, 2005.

[20] J. H. Kim, S. H. Lee, and N. I. Cho, "Bayesian image interpolation based on the learning and estimation of higher band wavelet coefficients," IEEE Int. Conf. on Image Pro., pp. 685-688, Atlanta, USA, October 2006

[21] H. C. Kim, J. G. Kuk, H. S. Song, S. H. Lee, M. J. Choi, N. I. Cho, "IKONOS image fusion by minimisation of spectral distortion using MAP estimator," Electronics Letters, pp. 970-971, August 2007.

저 자 소 개

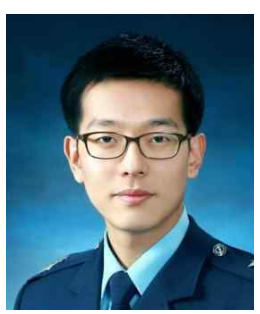

이 영 건

- 2005년 : 공군사관학교 무기기초학과, 학사

- 2009년 : 서울대학교 전기공학부, 석사

- 2009년 현재 : 공군사관학교 전자전산학과, 전임강사

- 주관심분야 : 영상처리, 컴퓨터비젼

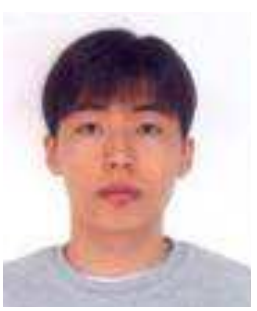

\section{국 중 갑}

- 2004년 : 서울대학교 전기공학부, 학사

- 2006년 : 서울대학교 전기공학부, 석사

- 2006년 현재 : 서울대학교 전기공학부, 박사과정

- 주관심분야 : 영상처리, 컴퓨터비젼

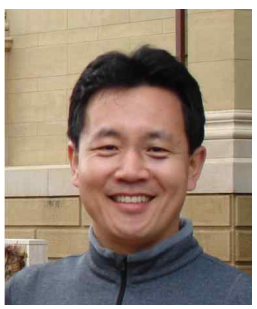

\section{조 남 익}

- 1986년 : 서울대학교 제어계측공학과, 학사

- 1988년 : 서울대학교 제어계측공학과, 석사

- 1992년 : 서울대학교 제어계측공학과, 박사

- 1991년 1994년 : 제어계측신기술연구센터, 연구원

- 1994년 1998년 : 서울시립대학교 전자전기공학부, 조교수

- 1999년 현재 : 서울대학교 전기공학부, 조교수, 부교수, 교수

- 주관심분야 : 디지털 신호처리 